\title{
Development of an autophagy-related gene expression signature for prognosis prediction in prostate cancer patients
}

Daixing Hu', Li Jiang ${ }^{1}$, Shengjun Luo ${ }^{1}$, Xin Zhao' ${ }^{1}, \mathrm{Hao} \mathrm{Hu}{ }^{2}$, Guozhi Zhao ${ }^{1}$ and Wei Tang ${ }^{1 *}$

\begin{abstract}
Background: Prostate cancer (PCa) is one of the most prevalent cancers that occur in men worldwide. Autophagyrelated genes (ARGs) may play an essential role in multiple biological processes of prostate cancer. However, ARGs expression signature has rarely been used to investigate the association between autophagy and prognosis in PCa. This study aimed to identify and assess prognostic ARGs signature to predict overall survival (OS) and disease-free survival (DFS) in PCa patients.
\end{abstract}

Methods: First, a total of 234 autophagy-related genes were obtained from The Human Autophagy Database. Then, differentially expressed ARGs were identified in prostate cancer patients based on The Cancer Genome Atlas (TCGA) database. The univariate and multivariate Cox regression analysis was performed to screen hub prognostic ARGs for overall survival and disease-free survival, and the prognostic model was constructed. Finally, the correlation between the prognostic model and clinicopathological parameters was further analyzed, including age, T status, N status, and Gleason score.

Results: The OS-related prognostic model was constructed based on the five ARGs (FAM215A, FDD, MYC, RHEB, and ATG16L1) and significantly stratified prostate cancer patients into high- and low-risk groups in terms of OS $(\mathrm{HR}=6.391,95 \% \mathrm{Cl}=1.581-25.840, \mathrm{P}<0.001)$. The area under the receiver operating characteristic curve (AUC) of the prediction model was 0.84 . The OS-related prediction model values were higher in T3-4 than in $\mathrm{T} 1-2(\mathrm{P}=0.008)$, and higher in Gleason score $>7$ than $\leq 7(P=0.015)$. In addition, the DFS-related prognostic model was constructed based on the 22 ARGs (ULK2, NLRC4, MAPK1, ATG4D, MAPK3, ATG2A, ATG9B, FOXO1, PTEN, HDAC6, PRKN, HSPB8, P4HB, MAP2K7, MTOR, RHEB, TSC1, BIRC5, RGS19, RAB24, PTK6, and NRG2), with AUC of 0.85 (HR=7.407, 95\% $C l=4.850-11.320, P<0.001)$, which were firmly related to T status $(P<0.001), N$ status $(P=0.001)$, and Gleason score $(\mathrm{P}<0.001)$.

Conclusions: Our ARGs based prediction models are a reliable prognostic and predictive tool for overall survival and disease-free survival in prostate cancer patients.

Keywords: TCGA, GEO, Prostate cancer, Survival, Autophagy

\footnotetext{
*Correspondence: tangwei2060@163.com

1 Department of Urology, The First Affiliated Hospital of Chongqing

Medical University, No.1 Youyi Road, Yuan Jiagang, Yuzhong District, Chongqing 400010, People's Republic of China

Full list of author information is available at the end of the article
}

\begin{abstract}
Background
Autophagy is a process that maintains cellular homeostasis, which conducts damaged or defective intracellular components, also known as type II programmed cell death [1]. Abnormal autophagy function is closely associated with multiple diseases, such as immune disorders, neurodegenerative diseases, and cancers [2].
\end{abstract}

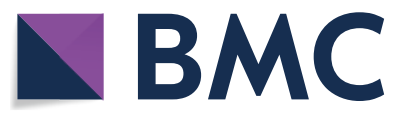

(c) The Author(s) 2020. This article is licensed under a Creative Commons Attribution 4.0 International License, which permits use, sharing, adaptation, distribution and reproduction in any medium or format, as long as you give appropriate credit to the original author(s) and the source, provide a link to the Creative Commons licence, and indicate if changes were made. The images or other third party material in this article are included in the article's Creative Commons licence, unless indicated otherwise in a credit line to the material. If material is not included in the article's Creative Commons licence and your intended use is not permitted by statutory regulation or exceeds the permitted use, you will need to obtain permission directly from the copyright holder. To view a copy of this licence, visit http://creativeco mmons.org/licenses/by/4.0/. The Creative Commons Public Domain Dedication waiver (http://creativecommons.org/publicdomain/ zero/1.0/) applies to the data made available in this article, unless otherwise stated in a credit line to the data. 
Several studies reported that autophagy could play a role in tumor progression or tumor suppression in different stages of cancers $[3,4]$. However, the role of autophagy in tumorigenesis is still rudimentary.

Prostate cancer $(\mathrm{PCa})$ is a common malignancy of the urinary system and the second cause of cancerrelated death of males in western developed countries [5]. In China, the annual incidence of PCa was more than 60,000 cases and 26,600 patients who succumbed to $\mathrm{PCa}$ in 2015 [6]. The majority of early-stage PCa patients have an excellent prognosis with a low mortality rate [7]. However, there are still a large number of PCa patients who develop the resistance to androgen deprivation therapy (ADT) and become castrationresistant $\mathrm{PCa}(\mathrm{CRPC})$, which results in a short survival time [8].

The relationship between autophagy and multiple biological processes of prostate cancer has been previously reported [9]. For instance, in the early stage of $\mathrm{PCa}$, autophagy may increase tumor cell death. However, elevated autophagy promotes prostate cancer invasion and progression and reduces the damage of chemotherapy drugs in the late stage. Cao et al. showed that the induction of autophagy might increase susceptibility to radiation in prostate cancer cell lines [10, 11]. However, large-scale gene expression signature has rarely been used to investigate the association between autophagy and prognosis in prostate cancer. To better understand the impact of tumor genetic composition on clinical outcomes, the Cancer Genome Atlas (TCGA) database has been established for discovering gene signatures.

There are many research and prognostic models based on gene expression profiles in prostate cancer, such as lncRNAs and miRNAs [12]. Nevertheless, prognostic models for autophagy-related genes have not been reported. In this study, we used gene expression microarray data obtained from TCGA to develop autophagy-related gene expression signature and develop a prognostic model as an independent index for overall survival (OS) and disease-free survival (DFS).

\section{Methods}

\section{Data acquisition}

A total of 234 autophagy-related genes were obtained from The Human Autophagy Database (HADb, http://www.autophagy.lu/index.html). RNA-seq data for prostate cancer patients were downloaded from the TCGA data portal (https://tcga-data.nci. nih.gov/tcga/), which contains 485 prostate cancer and 51 adjacent non-tumor tissues. We searched the cBio Cancer Genomics Portal (http://cbioportal.org) to identify the clinical data, including OS and DFS.

\section{Differentially expressed ARGs and enrichment analysis}

Data analysis of differential expression of ARGs between $\mathrm{PCa}$ and their non-tumor counterparts was performed using package limma in $\mathrm{R}$, with thresholds of $\mid \log _{2}$ fold change (FC) $\mid>2$ and adjusted P-value $<0.05$. Then, we performed gene ontology (GO) enrichment analyses to find the major biological attributes of differential expression ARGs. The visual GO enrichment maps of annotation analysis results were performed by R with the "ggplot2" and "GOplot" packages.

\section{Construction of prognostic signature based on ARGs}

Univariate Cox and multivariate Cox regression analyses were performed to find out the OS-related and DFS-related ARGs in PCa. Then, the OS-related and DFS-related prediction formulas were applied to build prognostic models using package "glmnet" based on the multivariate Cox regression. The survival analysis was assessed by Kaplan-Meier (K-M) methods to compare the high-risk and low-risk groups according to predictive signatures. Finally, the predictive value of prognostic prediction models was evaluated by areas under the curve (AUC) of the receiver-operator characteristic (ROC) curve using package "survivalROC" in R.

\section{Statistical analysis}

All of the statistical tests were done with R 3.3.1 (https ://www.r-project.org/) and GraphPad Prism 7 (San Diego, CA, USA). All analyses performed were twosided, and statistical significance was defined as a P-values $<0.05$.

\section{Results}

Differentially expressed ARGs between prostate cancer and adjacent non-tumor tissues

A total of 485 primary PCa patients with RNA-seq data and clinical follow-up information were involved in the present study. Among 234 autophagy-related genes, there were 13 differentially expressed ARGs, including 5 up-regulated (ATG9B, BIRC5, CAMKK2, CDKN2A, and NKX2-3) and 8 down-regulated ARGs (DNAJB1, FAM215A, HSPB8, ITGB4, ITPR1, NRG1, NRG2, and TP63), with thresholds of $\mid \log _{2}$ fold change (FC) $\mid>2$ (Fig. 1a). Then, the volcano plot and box plot were visualized to show the expression pattern of the differentially expressed ARGs between PCa and non-tumor tissues (Fig. 1b, c). 


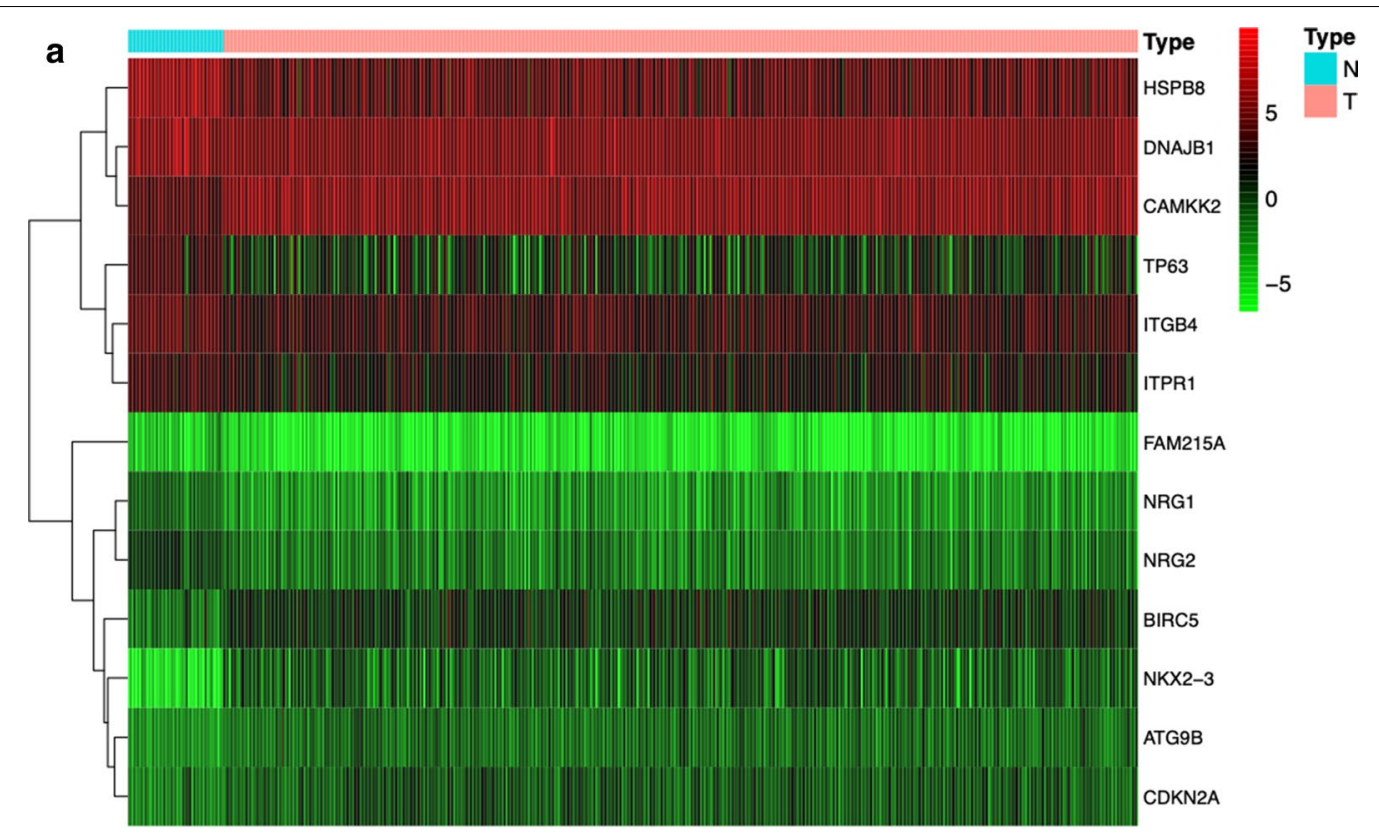

b

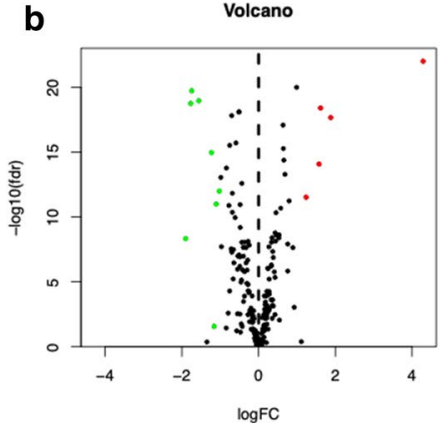

C

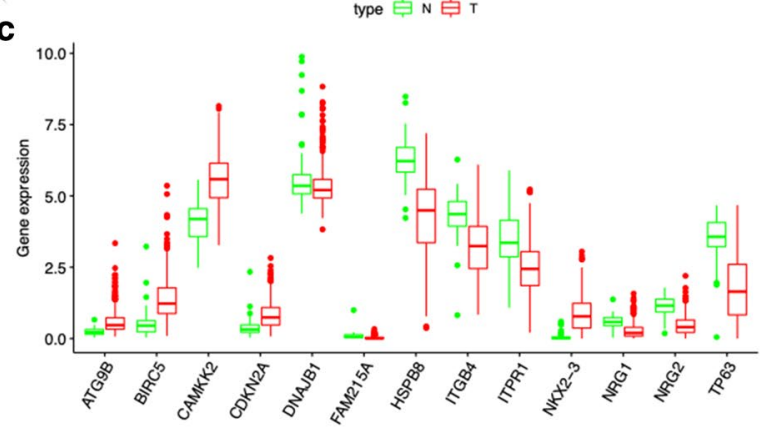

Fig. 1 Differentially expressed ARGs between prostate cancer and normal prostate tissues. a Heatmap of differentially expressed ARGs. b The volcano plot for the 234 ARGs from the TCGA data portal. Red indicates high expression, and green indicates low expression. Black shows that those genes showed no difference between prostate cancer and normal prostate tissues. c The expression patterns of 13 differentially expressed ARGs in prostate cancer and paired non-tumor samples. Red and green indicate tumor tissues and normal tissues, respectively

\section{GO enrichment analysis of differentially expressed autophagy-related genes}

GO enrichment analysis was performed according to the differentially expressed ARGs. According to the results of DAVID, we found that the top enriched GO terms for biological processes were autophagy, process utilizing autophagic mechanism, and odontogenesis of dentin-containing tooth. The heatmap of the relationship between ARGs and GO enrichment analysis was also displayed (Fig. 2a, b).

\section{Identification of prognosis-related ARGs and construction of prognosis prediction model}

A total of 14 ARGs were significantly associated with OS in the univariate Cox regression analysis. Furthermore, in the multivariate Cox regression analysis, five genes including FAM215A, FDD, MYC, RHEB, and ATG16L1 were identified to construct the OS prediction model. OS-related prediction model $=\left(17.20896^{*}\right.$ expression value of FAM215A $)+\left(4.319028^{*}\right.$ expression value of $\mathrm{FADD})+\left(0.674838^{*}\right.$ expression value of $\mathrm{MYC})+\left(1.869633^{*}\right.$ expression value of RHEB $)+\left(2.071004^{*}\right.$ expression value of ATG16L1).

We divided the 485 prostate cancer cases into highand low-risk groups according to the median values of the OS-related prediction model. Kaplan-Meier survival curves showed that low-risk group had a lower mortality rate than high-risk group $(\mathrm{HR}=6.391,95 \% \mathrm{CI}=1.581$ 25.840, $\mathrm{P}<0.001$ ) (Fig. 3a). The ROC curves of OS-related predictive signatures were demonstrated in Fig. 3b, with 
a
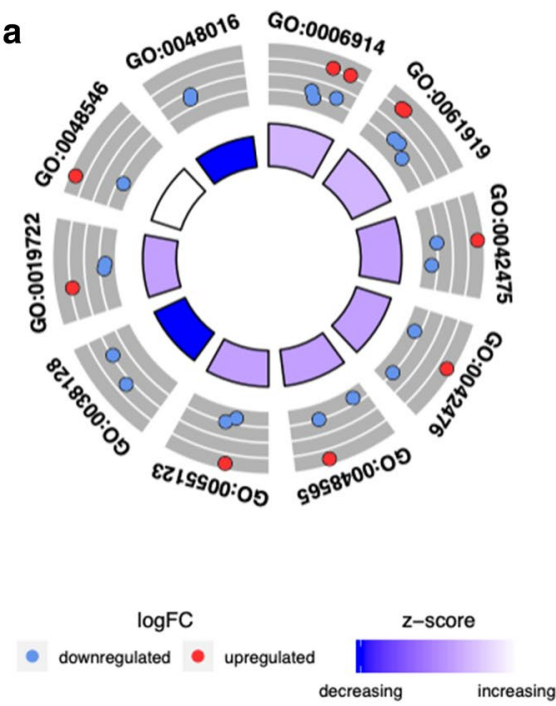

b process utilizing autophagic mechanism odontogenesis of dentin-containing toothodontogenesis . inositol phosphate-mediated signaling . ERBB2 signaling pathway. digestive tract morphogenesis digestive tract development digestive system development calcium-mediated signaling autophagy -

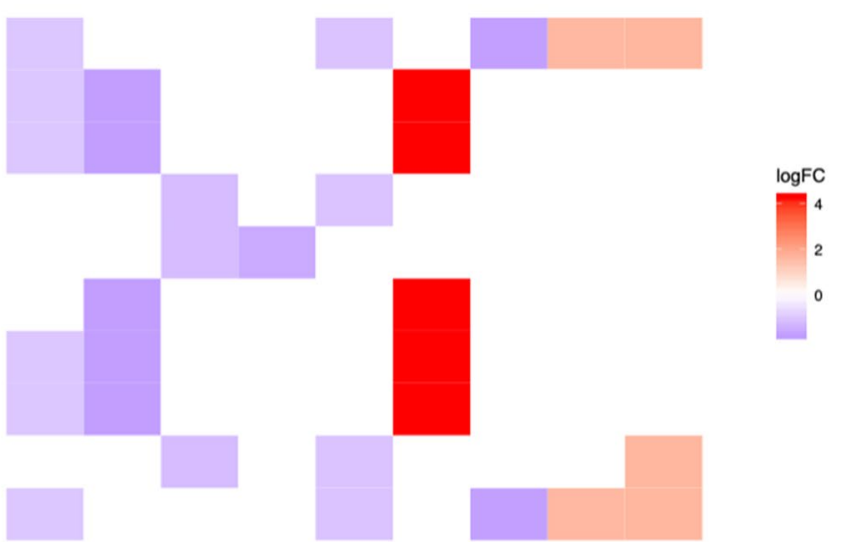

Fig. 2 GO enrichment analysis of differentially expressed autophagy-related genes. a The outer circle shows a scatter plot for each term of the $\log F C$ of the differentially expressed ARGs. $\mathbf{b}$ Heatmap of the relationship between ARGs and GO enrichment. The color of each block depends on the logFC values

AUC of 0.84. Figure 3c, d showed the OS-related prediction model distribution of patients in the TCGA dataset.

According to the median value of the five genes, the high expression level of FAM215A ( $\mathrm{HR}=4.347,95 \%$ $\mathrm{CI}=1.175-16.290, \mathrm{P}=0.041), \mathrm{FADD}(\mathrm{HR}=7.009,95 \%$ $\mathrm{CI}=1.892-25.960, \mathrm{P}=0.031)$, and $\mathrm{MYC}(\mathrm{HR}=7.153$, 95\% $\mathrm{CI}=1.932-26.470, \quad \mathrm{P}=0.029$ ) were significantly associated with worse OS in Kaplan-Meier curves (Fig. 4). However, this association did not hold true of gene ATG16L1(HR $=2.426,95 \% \mathrm{CI}=0.653-9.017$, $\mathrm{P}=0.194)$ and RHEB $(\mathrm{HR}=1.236,95 \% \mathrm{CI}=0.335-4.566$, $\mathrm{P}=0.744$ ) in Kaplan-Meier curves (Additional file 1 : Fig. S1).

Among 234 autophagy-related genes, a total of 53 ARGs were significantly associated with DFS in the univariate Cox regression analysis. In the multivariate Cox regression analysis, a total of 22 genes

\begin{tabular}{|c|c|}
\hline ID & Description \\
\hline GO:0006914 & autophagy \\
\hline GO:0061919 & process utilizing autophagic mechanism \\
\hline GO:0042475 & odontogenesis of dentin-containing tooth \\
\hline GO:0042476 & odontogenesis \\
\hline GO:0048565 & digestive tract development \\
\hline GO:0055123 & digestive system development \\
\hline GO:0038128 & ERBB2 signaling pathway \\
\hline GO:0019722 & calcium-mediated signaling \\
\hline GO:0048546 & digestive tract morphogenesis \\
\hline GO:0048016 & inositol phosphate-mediated signaling \\
\hline
\end{tabular}

$\log F$

\section{(1)}




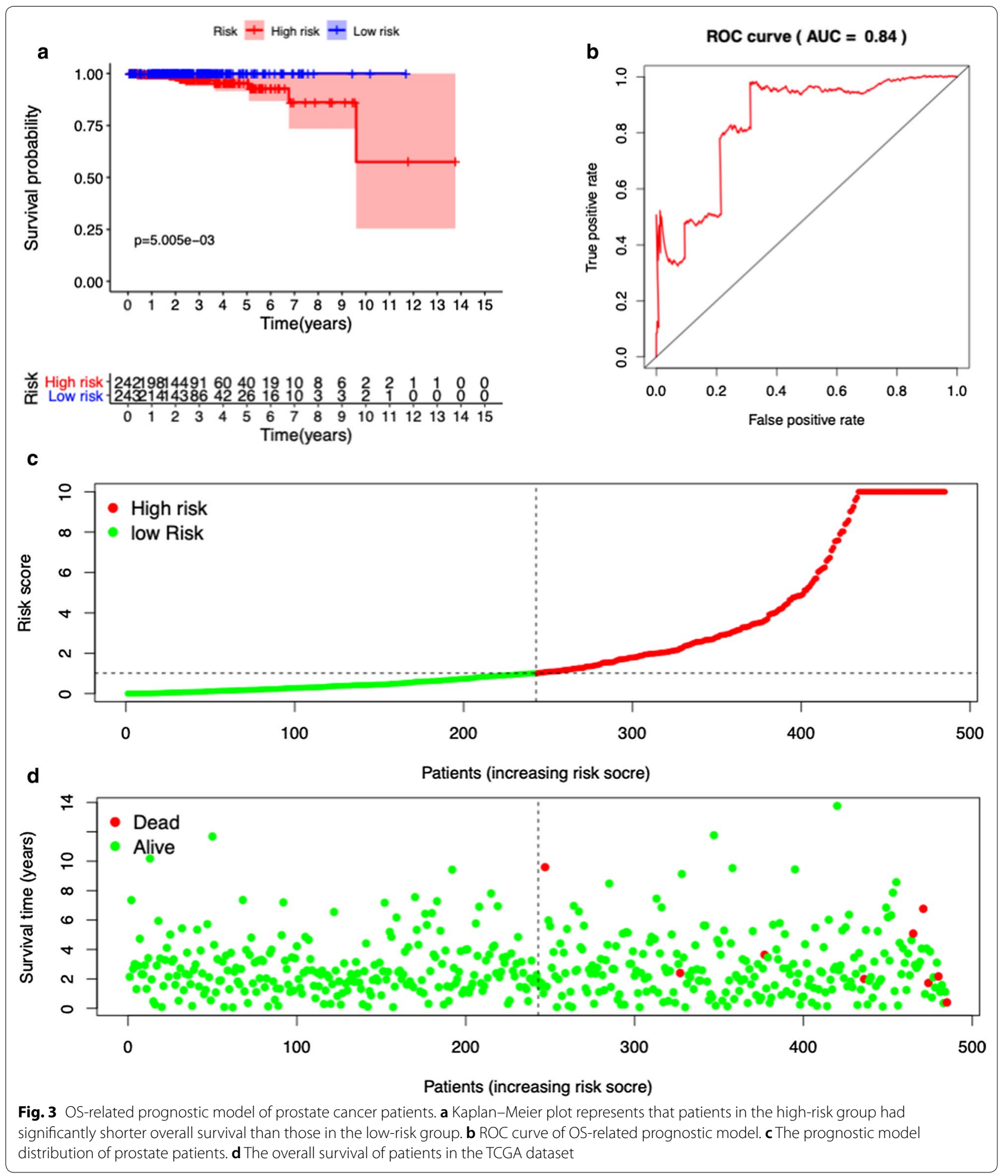

RHEB $)+(0.73934 *$ expression value of TSC1 $)+(0.27799 *$ expression value of BIRC5 $)+\left(1.43484^{*}\right.$ expression value of $\mathrm{RGS19})+\left(-0.63037^{*}\right.$ expression value of $\mathrm{RAB} 24)+\left(-0.28580^{*}\right.$ expression value of PTK6) + (-1.05312* expression value of NRG2).

We divided the PCa cases into high- and lowrisk groups according to the median values of the 

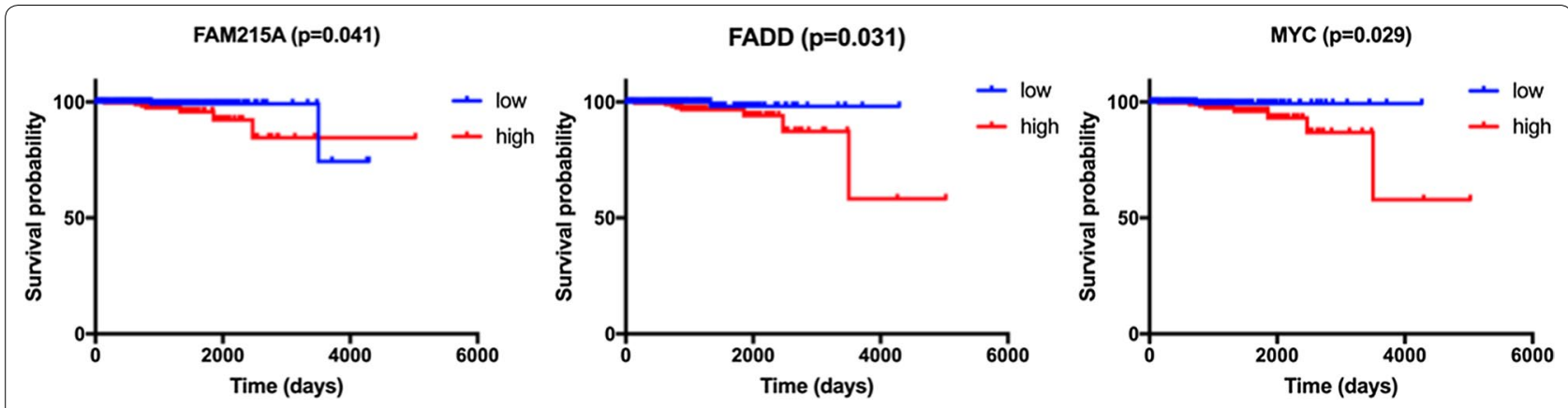

Fig. 4 The correlation between ARGs included in OS-related prognostic signature and prostate cancer patients'survival

DFS-related prediction model. Kaplan-Meier survival curves showed that high-risk group had a lower disease-free rate than low-risk group $(\mathrm{HR}=7.407$, 95\% CI $=4.850-11.320, \mathrm{P}<0.001)$. The ROC curves of OS-related predictive signatures were demonstrated in Fig. 5b, with AUC of 0.85. Figure 5c, d showed the DFS-related prediction model distribution of patients in the TCGA dataset.

Among the 22 genes in DFS-related prediction model, high expression of ATG2A $(\mathrm{HR}=2.266,95 \%$ $\mathrm{CI}=1.492-3.442, \mathrm{P}<0.001), \mathrm{ATG} 4 \mathrm{D}(\mathrm{HR}=1.665,95 \%$ $\mathrm{CI}=1.096-2.530, \mathrm{P}=0.017)$, ATG9B $(\mathrm{HR}=1.803,95 \%$ $\mathrm{CI}=1.187-2.738, \mathrm{P}=0.007)$, BIRC5 $(\mathrm{HR}=2.013,95 \%$ $\mathrm{CI}=1.384-3.195, \mathrm{P}<0.001)$, MAPK3 $(\mathrm{HR}=2.148,95 \%$ $\mathrm{CI}=1.414-3.263, \mathrm{P}<0.001), \mathrm{NLRC} 4(\mathrm{HR}=2.053,95 \%$ $\mathrm{CI}=1.352-3.119, \mathrm{P}=0.001), \mathrm{RAB} 24(\mathrm{HR}=2.811,95 \%$ $\mathrm{CI}=1.851-4.270, \mathrm{P}<0.001), \mathrm{RGS} 19(\mathrm{HR}=2.019,95 \%$ $\mathrm{CI}=1.329-3.068, \mathrm{P}=0.001), \mathrm{RHEB}(\mathrm{HR}=2.137,95 \%$ $\mathrm{CI}=1.407-3.245, \mathrm{P}<0.001), \mathrm{ULK} 2 \quad(\mathrm{HR}=1.579,95 \%$ $\mathrm{CI}=1.039-2.399, \mathrm{P}=0.033)$, and $\mathrm{TSC} 1 \quad(\mathrm{HR}=1.622$, $95 \% \mathrm{CI}=1.067-2.464, \mathrm{P}=0.024)$ genes were associated with worse prognosis in PCa in Kaplan-Meier curves according to the median values of gene expression (Fig. 6). In addition, high expression of FOXO1 $(\mathrm{HR}=2.087,95 \% \mathrm{CI}=1.373-3.172, \mathrm{P}<0.001)$, HSPB8 $(\mathrm{HR}=1.673,95 \% \mathrm{CI}=1.101-2.541, \mathrm{P}=0.017), \mathrm{MTOR}$ $(\mathrm{HR}=1.897,95 \% \mathrm{CI}=1.247-2.885, \mathrm{P}=0.002), \mathrm{NRG} 2$ $(\mathrm{HR}=1.944,95 \% \mathrm{CI}=1.280-2.955, \mathrm{P}=0.002)$ and PRKN $(\mathrm{HR}=2.308,95 \% \mathrm{CI}=1.518-3.508, \mathrm{P}<0.001)$ genes were associated with better prognosis in KaplanMeier curves according to the median values of gene expression (Fig. 7). No differences were found between the expression level of HDAC6 $(\mathrm{HR}=1.392,95 \%$ $\mathrm{CI}=0.913-2.123, \mathrm{P}=0.116), \mathrm{MAP} 2 \mathrm{~K} 7 \quad(\mathrm{HR}=1.379$, 95\% $\quad \mathrm{CI}=0.908-2.094, \quad \mathrm{P}=0.133), \quad$ MAPK1 $(\mathrm{HR}=1.426,95 \% \mathrm{CI}=0.939-2.167, \mathrm{P}=0.095), \mathrm{P} 4 \mathrm{HB}$ $(\mathrm{HR}=1.501,95 \% \mathrm{CI}=0.988-2.280, \mathrm{P}=0.058)$, РTK6 $(\mathrm{HR}=1.338,95 \% \mathrm{CI}=0.881-2.032, \mathrm{P}=0.174)$, and
PTEN $(\mathrm{HR}=1.324,95 \% \mathrm{CI}=0.872-2.010, \mathrm{P}=0.191)$ and disease-free survival (Additional file 2: Fig. S2).

\section{The relationships between clinicopathological parameters and prognosis-related ARGs and prognosis-related prediction model}

The OS-related prediction model values were higher in T3-4 than in $\mathrm{T} 1-2(\mathrm{P}=0.008)$, and higher in Gleason score $>7$ than $\leq 7(\mathrm{P}=0.015)$. No difference of OSrelated prediction model values was observed between age $>65$ than age $\leq 65(\mathrm{P}=0.164)$, or N0 stage and N1 stage $(\mathrm{P}=0.088)$ (Fig. 8$)$. The DFS-related prediction model values were higher in T3-4 than in T1-2 $(\mathrm{P}<0.001)$, higher in $\mathrm{N} 1$ than in N0 $(\mathrm{P}=0.001)$, and higher in Gleason score $>7$ than $\leq 7(\mathrm{P}<0.001)$. No difference of DFSrelated prediction model values was observed between age $>65$ than age $\leq 65(\mathrm{P}=0.208)$ (Fig. 9).

Among 485 primary PCa patients in the present study, only two of them had distant metastasis. Therefore, the relationship between the $M$ status and prediction model has not been analyzed.

\section{Discussion}

Much evidence has indicated that autophagy participates in multiple signaling pathways to play a role in the proliferation and invasion of prostate cancer $[9,13]$. Additionally, Blessing et al. demonstrated that four core autophagy genes (ATG4B, ATG4D, ULK1, and ULK2) regulate androgen receptor (AR) activity, thereby affecting the biological behavior of prostate cancer [14].

In the present study, we mined the expression profiles of ARGs from the TCGA database and aimed to analyze the association between ARGs and the prognosis of prostate cancer patients. Firstly, we screened 13 differentially expressed ARGs between prostate cancer and non-tumor tissues, that many of them play a role in the biological processes by GO term analysis. 


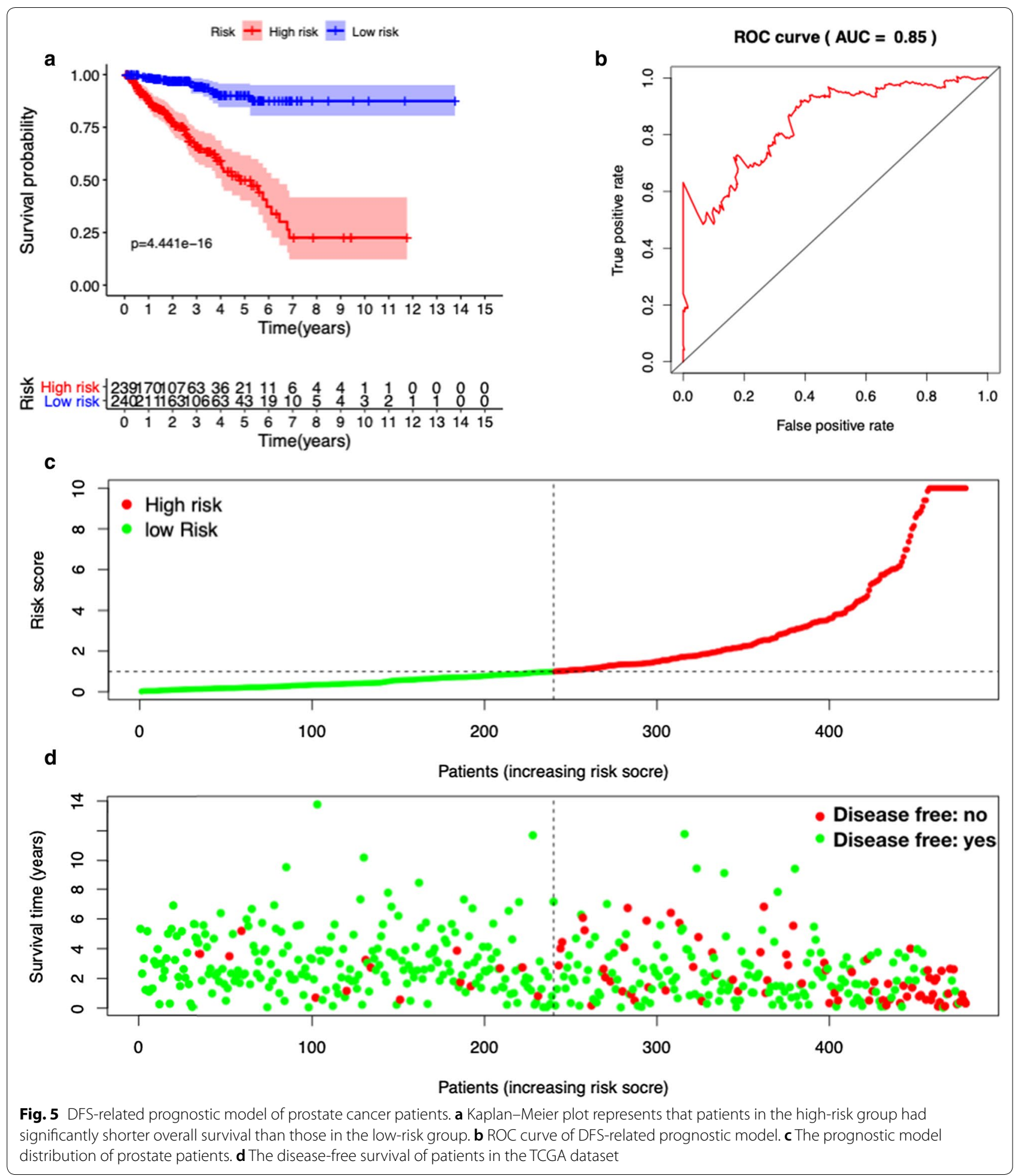

Then, a total of 14 OS-related ARGs were found in the univariate Cox regression analysis. Further multivariate Cox regression analysis was performed to determine five OS-related ARGs (FAM215A, FDD, MYC, RHEB, and ATG16L1) and construct the OS-related prediction model, which could be an independent prognostic indicator for PCa patients. 


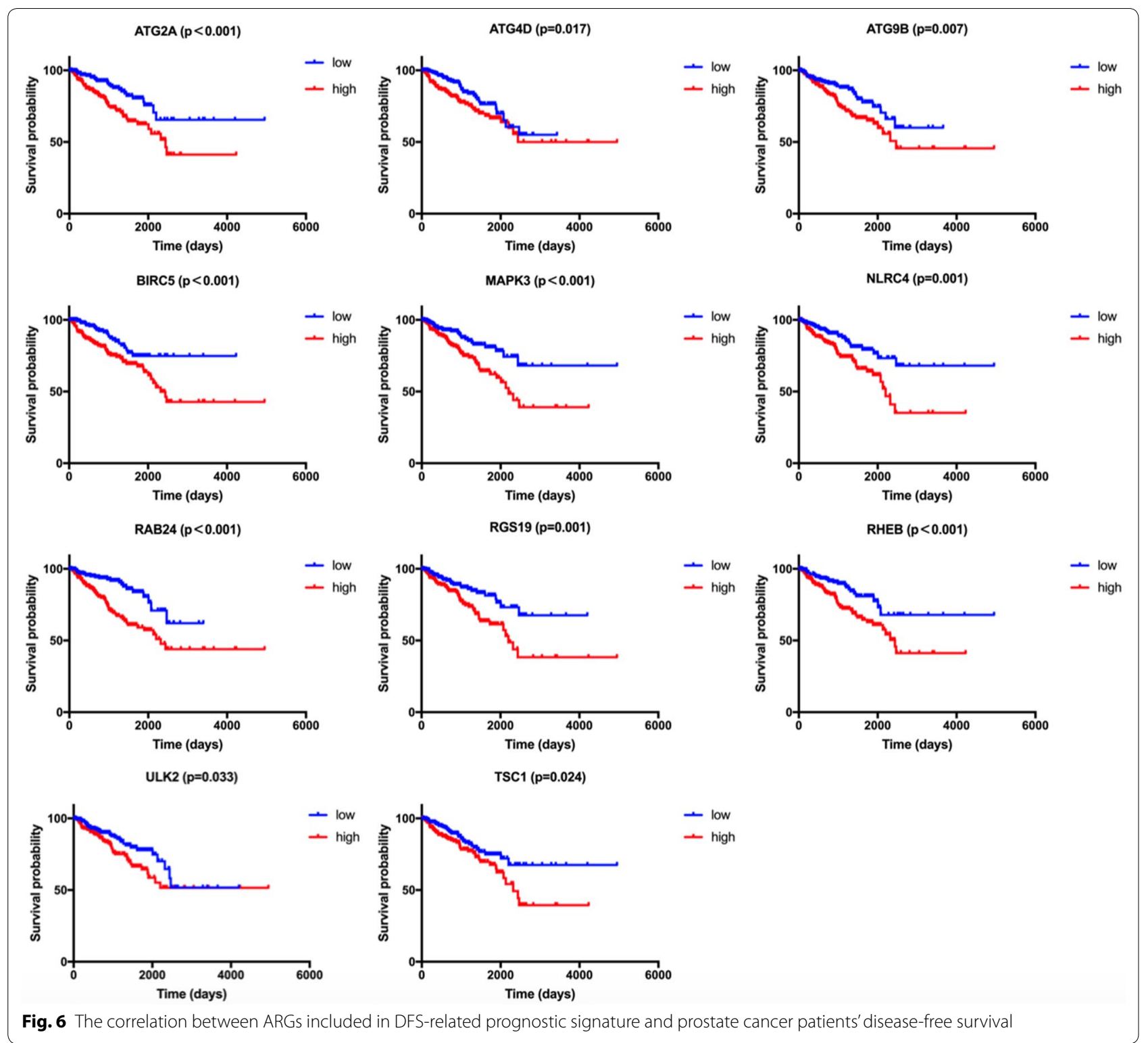

Handle et al. found that MYC activity is closely related to AR, which regulates the growth of anti-androgen resistant cell lines [15]. Kobayashi et al. demonstrated that RHEB mRNA and protein expression was higher in more aggressive prostate cancer cell lines (PC3 and DU145) compared with the less aggressive LNCaP. Moreover, inhibition of RHEB can lead to the suppressed proliferation of prostate cancer cell lines [16]. Previous research analyzed the relationship between genetic variants of the autophagy pathway and clinical outcomes in 458 prostate cancer patients, which indicated that high expression of ATG16L1 was correlated with lower tumor aggressiveness and favorable prognosis [17]. Fu et al. reported that high expression of FAM215A was associated with low tumor grades, early disease stages, and favorable overall survival in epithelial ovarian cancer [18]. FDD is a component of FMNL3, and high expression of FMNL3 associated with cancer cell migration, invasion, and unfavorable prognosis in tongue squamous cell carcinoma [19]. However, the function of FAM215A and FDD gene has not been reported in prostate cancer, indicating that functional studies on these genes may help us to understand the prognosis-related biological behavior of bladder cancers more accurately.

In the present study, a total of 22 ARGs were significantly associated with DFS of PCa in multivariate Cox regression analysis, including ULK2, NLRC4, MAPK1, ATG4D, MAPK3, ATG2A, ATG9B, FOXO1, PTEN, 

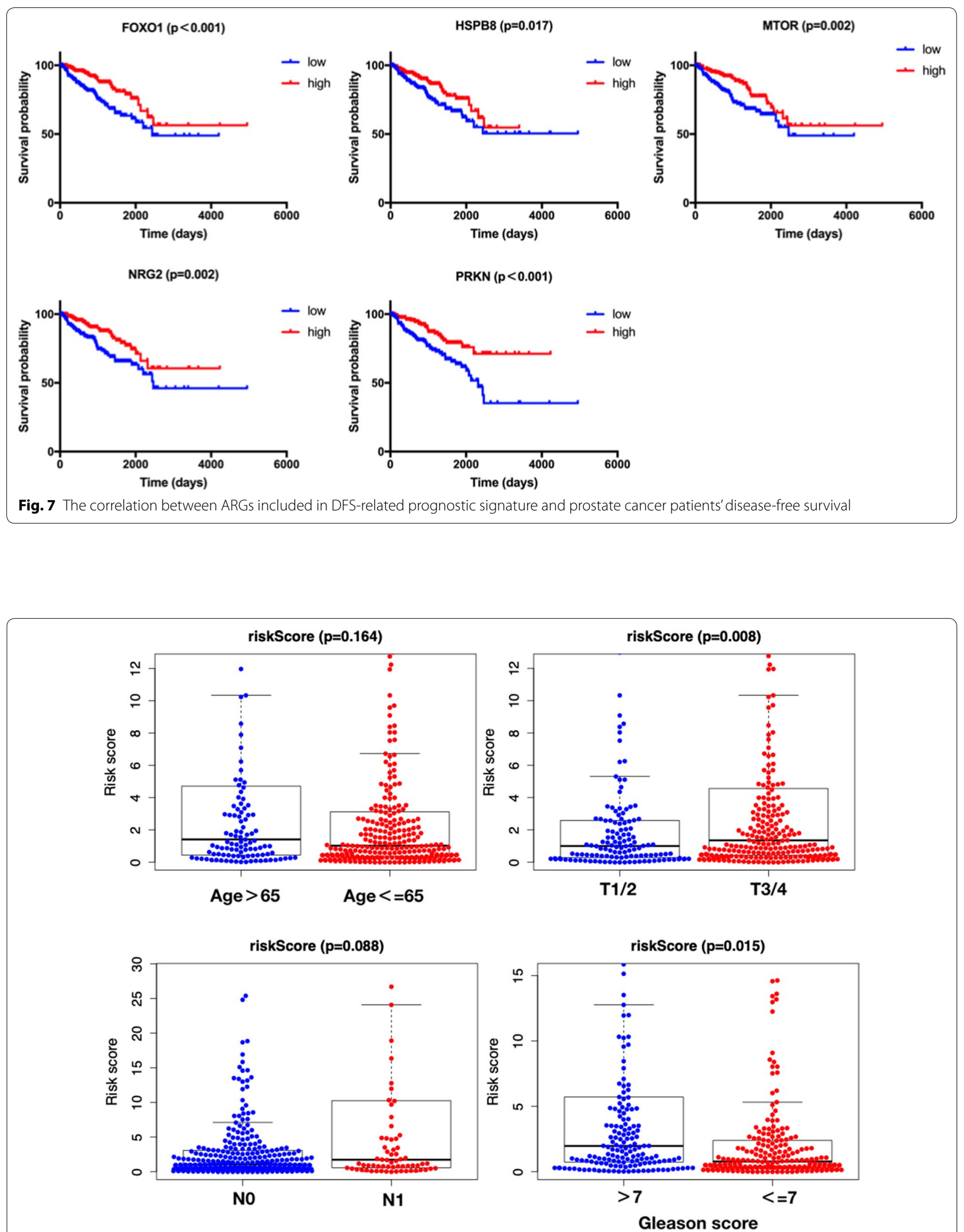

Fig. 8 The clinicopathological significance of OS-related prognostic model in prostate cancer 

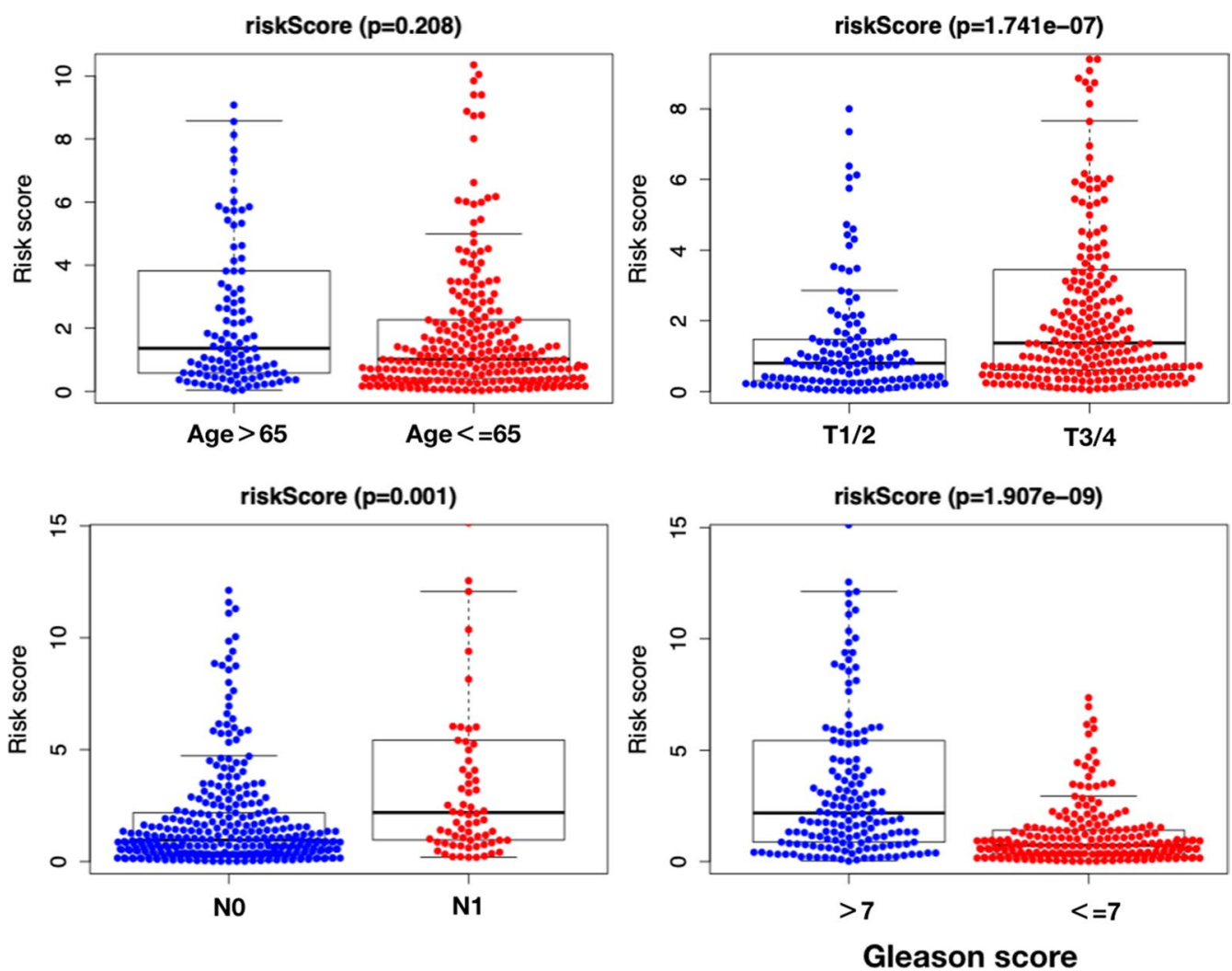

Fig. 9 The clinicopathological significance of DFS-related prognostic model in prostate cancer

HDAC6, PRKN, HSPB8, P4HB, MAP2K7, MTOR, RHEB, TSC1, BIRC5, RGS19, RAB24, PTK6, and NRG2. Previous research has shown that ULK2 and ATG4D were hub autophagy genes, which are necessary for maximal androgen-mediated autophagy and cell proliferation and also associated with poor prognosis in PCa [14]. Li et al. demonstrated that MAPK1 plays an important role in regulating cancer cell invasion and metastasis in vitro and in vivo [20]. Forkhead box transcription factor-1 (FOXO1) is a tumor suppressor that is downregulated in human prostate cancer, which acts as a repression target of EZH2 and an essential mediator of EZH2 inhibition-induced cell death [21]. PTEN is one of the most commonly altered tumor suppressor genes in prostate cancer, which negatively regulates the $\mathrm{PI} 3 \mathrm{~K} / \mathrm{AKT} / \mathrm{mTOR}$ signaling pathway. PTEN deletion is associated with poorer cancer-specific outcomes, increasing stage, and higher Gleason score [22]. Chuang et al. suggested that HDAC6 has anti-cancer activity in prostate cancer, which participates in regulating the cRaf-PP1-ERK signaling pathway and contributing to $\mathrm{M}$ phase cell-cycle transition [23]. Many studies have shown that multiple oncogenes promote $\mathrm{PCa}$ cell proliferation, migration, invasion, and inhibiting apoptosis through activating the PI3KAKT-mTOR signaling pathway [24]. Chen et al. found that the high levels of NPRL2 gene expression in prostate cancer cells promote resistance to EVS (an inhibitor of the mTOR) by enhancing autophagy [25]. In addition, TSC1 was significantly associated with DFS in $\mathrm{PCa}$, which is an essential component of the PI3K/ AKT/mTOR signaling pathway [26]. Among the 22 DFS-related ARGs, except for those mentioned above, other ARGs are either poorly investigated or have not been reported, which means our findings suggested further research for them is imperative.

The OS and DFS-related prediction model values were both associated with the $\mathrm{T}$ stage and Gleason score in PCa patients, higher in T3/4 than in T1/2, and higher in Gleason score $>7$ than $\leq 7$. Patients with $\mathrm{T} 3$ or $\mathrm{T} 4$ stage are also known as locally advanced prostate cancer. Krimphove et al. reported that PCa with T3 or T4 had a worse overall survival [27]. Meanwhile, the Gleason score is the sum of the two most common grade patterns in $\mathrm{PCa}$, which act as the single most potent predictor of PCa outcomes [28]. DFS-related prediction model values were higher in N1 than in N0. N1 is defined as regional lymph node metastasis in AJCC/UICC N category. Jin 
et al. proposed lymph node ratio (LNR) and log odds of metastatic lymph node (LODDS) staging may be better predictors of overall survival than the AJCC/UICC N category [29]. Accumulating evidence indicates that the characteristics of gene expression are significantly correlated with the patient's adverse clinical parameters.

\section{Conclusion}

In conclusion, our current study assessed the autophagyrelated genes expression profiles based on the TCGA database. It proposed an OS-related and a DFS-related prediction model, which had good efficacy in predicting the OS and DFS of PCa patients. A total of five OS-related ARGs (FAM215A, FDD, MYC, RHEB, and ATG16L1) and twenty-two DFS-related ARGs (ULK2, NLRC4, MAPK1, ATG4D, MAPK3, ATG2A, ATG9B, FOXO1, PTEN, HDAC6, PRKN, HSPB8, P4HB, MAP2K7, MTOR, RHEB, TSC1, BIRC5, RGS19, RAB24, PTK6, and NRG2) were identified. These results showed that the autophagyrelated genes signature may act as a promising prognostic molecular biomarker in PCa. Moreover, further research of these hub genes may contribute to molecular targeted therapy of prostate cancer.

\section{Supplementary information}

Supplementary information accompanies this paper at https://doi. org/10.1186/s12967-020-02323-x.

Additional file 1: Figure S1. The correlation between ATG16L1 and RHEB and OS in Kaplan-Meier curves.

Additional file 2: Figure S2. The correlation between HDAC6, MAP2K7, MAPK1, P4HB, PTK6, and PTEN and DFS in Kaplan-Meier curves.

\section{Abbreviations}

PCa: Prostate cancer; ARGs: Autophagy-related genes; TCGA: The genomic data commons data portal and the cancer genome atlas database; GO: Gene ontology database; ROC curve: Receiver operating characteristic curve; AUC: Area under curve; OS: Overall survival; DFS: Disease-free survival.

\section{Acknowledgements}

None.

\section{Authors' contributions}

Conceived and designed the study: DH, WT. Collected the literature: XZ, DH, GZ. Wrote the manuscript: DH, LJ, HH. Revised the manuscript: SL, WT. All authors read and approved the final manuscript.

\section{Funding}

None.

\section{Availability of data and materials}

Not applicable.

\section{Ethics approval and consent to participate}

Not applicable.

\section{Consent for publication}

Not applicable.

\section{Competing interests}

The authors declare that they have no competing interests.

\section{Author details}

${ }^{1}$ Department of Urology, The First Affiliated Hospital of Chongqing Medical University, No.1 Youyi Road, Yuan Jiagang, Yuzhong District, Chongqing 400010, People's Republic of China. ${ }^{2}$ Department of Urology, The People's Hospital of Nan Chuan, Chongqing 408400, People's Republic of China.

Received: 6 November 2019 Accepted: 28 March 2020

Published online: 07 April 2020

\section{References}

1. Lyamzaev KG, Tokarchuk AV, Panteleeva AA, Mulkidjanian AY, Skulachev VP, Chernyak BV. Induction of autophagy by depolarization of mitochondria. Autophagy. 2018;14:921-4.

2. Hernandez-Tiedra S, Fabrias G, Davila D, Salanueva IJ, Casas J, Montes LR, Anton Z, Garcia-Taboada E, Salazar-Roa M, Lorente M, et al. Dihydroceramide accumulation mediates cytotoxic autophagy of cancer cells via autolysosome destabilization. Autophagy. 2016:12:2213-29.

3. Tektemur A, Ozaydin S, Etem Onalan E, Kaya N, Kuloglu T, Ozercan IH, Tekin S, Elyas HM. TRPM2 mediates distruption of autophagy machinery and correlates with the grade level in prostate cancer. J Cancer Res Clin Oncol. 2019:145:1297-311.

4. Monkkonen T, Debnath J. Inflammatory signaling cascades and autophagy in cancer. Autophagy. 2018:14:190-8.

5. Jemal A, Ma J, Siegel R, Fedewa S, Brawley O, Ward EM. Prostate cancer incidence rates 2 years after the US preventive services task force recommendations against screening. JAMA Oncol. 2016;2:1657-60.

6. Chen W, Zheng R, Baade PD, Zhang S, Zeng H, Bray F, Jemal A, Yu XQ, He J Cancer statistics in China, 2015. CA Cancer J Clin. 2016;66:115-32.

7. Seikkula HA, Kaipia AJ, Ryynanen H, Seppa K, Pitkaniemi JM, Malila NK, Bostrom PJ. The impact of socioeconomic status on stage specific prostate cancer survival and mortality before and after introduction of PSA test in Finland. Int J Cancer. 2018;142:891-8.

8. Small EJ, Saad F, Chowdhury S, Oudard S, Hadaschik BA, Graff JN, Olmos $D$, Mainwaring PN, Lee JY, Uemura $\mathrm{H}$, et al. Apalutamide and overall survival in non-metastatic castration-resistant prostate cancer. Ann Oncol. 2019;30:1813-20

9. Zhao R, Bei X, Yang B, Wang X, Jiang C, Shi F, Wang X, Zhu Y, Jing Y, Han B, et al. Endothelial cells promote metastasis of prostate cancer by enhancing autophagy. J Exp Clin Cancer Res. 2018;37:221.

10. Cao C, Subhawong T, Albert JM, Kim KW, Geng L, Sekhar KR, Gi YJ, Lu B. Inhibition of mammalian target of rapamycin or apoptotic pathway induces autophagy and radiosensitizes PTEN null prostate cancer cells. Cancer Res. 2006;66:10040-7.

11. Zhang S, Li J, Zhou G, Mu D, Yan J, Xing J, Yao Z, Sheng H, Li D, Lv C, et al. Aurora-A regulates autophagy through the Akt pathway in human prostate cancer. Cancer Biomark. 2017;19:27-34.

12. Xiaoli Z, Yawei W, Lianna L, Haifeng L, Hui Z. Screening of target genes and regulatory function of miRNAs as prognostic indicators for prostate cancer. Med Sci Monit. 2015;21:3748-59.

13. Tao T, Zhao F, Xuan Q, Shen Z, Xiao J, Shen Q. Fenofibrate inhibits the growth of prostate cancer through regulating autophagy and endoplasmic reticulum stress. Biochem Biophys Res Commun. 2018;503:2685-9.

14. Blessing AM, Rajapakshe K, Reddy Bollu L, Shi Y, White MA, Pham AH, Lin C, Jonsson P, Cortes CJ, Cheung E, et al. Transcriptional regulation of core autophagy and lysosomal genes by the androgen receptor promotes prostate cancer progression. Autophagy. 2017;13:506-21.

15. Handle F, Prekovic S, Helsen C, Van den Broeck T, Smeets E, Moris L, Eerlings R, Kharraz SE, Urbanucci A, Mills IG, et al. Drivers of AR indifferent anti-androgen resistance in prostate cancer cells. Sci Rep. 2019;9:13786.

16. Kobayashi T, Shimizu Y, Terada N, Yamasaki T, Nakamura E, Toda Y, Nishiyama H, Kamoto T, Ogawa O, Inoue T. Regulation of androgen receptor transactivity and mTOR-S6 kinase pathway by Rheb in prostate cancer cell proliferation. Prostate. 2010;70:866-74.

17. Huang CY, Huang SP, Lin VC, Yu CC, Chang TY, Lu TL, Chiang HC, Bao BY. Genetic variants of the autophagy pathway as prognostic indicators for prostate cancer. Sci Rep. 2015;5:14045. 
18. Fu Y, Biglia N, Wang Z, Shen Y, Risch HA, Lu L, Canuto EM, Jia W, Katsaros D, Yu H. Long non-coding RNAs, ASAP1-IT1, FAM215A, and LINC00472, in epithelial ovarian cancer. Gynecol Oncol. 2016;143:642-9.

19. Liu J, Chen S, Chen Y, Geng N, Feng C. High expression of FMNL3 associates with cancer cell migration, invasion, and unfavorable prognosis in tongue squamous cell carcinoma. J Oral Pathol Med. 2019;48:459-67.

20. Li Y, Luo H, Xiao N, Duan J, Wang Z, Wang S. Long noncoding RNA SChLAP1 accelerates the proliferation and metastasis of prostate cancer via targeting miR-198 and promoting the MAPK1 pathway. Oncol Res. 2018;26:131-43.

21. Ma L, Yan Y, Bai Y, Yang Y, Pan Y, Gang X, Karnes RJ, Zhang J, Lv Q, Wu Q Huang $\mathrm{H}$. Overcoming EZH2 inhibitor resistance by Taxane in PTENmutated cancer. Theranostics. 2019;9:5020-34.

22. Murphy SJ, Karnes RJ, Kosari F, Castellar BE, Kipp BR, Johnson SH, Terra S, Harris FR, Halling GC, Klein JL, et al. Integrated analysis of the genomic instability of PTEN in clinically insignificant and significant prostate cancer. Mod Pathol. 2016;29:143-56.

23. Chuang MJ, Wu ST, Tang SH, Lai XM, Lai HC, Hsu KH, Sun KH, Sun GH, Chang SY, Yu DS, et al. The HDAC inhibitor LBH589 induces ERK-dependent prometaphase arrest in prostate cancer via HDAC6 inactivation and down-regulation. PLoS ONE. 2013;8:e73401.

24. Yan G, Ru Y, Wu K, Yan F, Wang Q, Wang J, Pan T, Zhang M, Han H, Li X, Zou L. GOLM1 promotes prostate cancer progression through activating PI3KAKT-mTOR signaling. Prostate. 2018;78:166-77.
25. Chen Z, Jiang Q, Zhu P, Chen Y, Xie X, Du Z, Jiang L, Tang W. NPRL2 enhances autophagy and the resistance to Everolimus in castrationresistant prostate cancer. Prostate. 2019;79:44-53.

26. Wu L, Yi B, Wei S, Rao D, He Y, Naik G, Bae S, Liu XM, Yang WH, Sonpavde $\mathrm{G}$, et al. Loss of FOXP3 and TSC1 accelerates prostate cancer progression through synergistic transcriptional and posttranslational regulation of c-MYC. Cancer Res. 2019;79:1413-25.

27. Krimphove MJ, Cole AP, Fletcher SA, Harmouch SS, Berg S, Lipsitz SR, Sun M, Nabi J, Nguyen PL, Hu JC, et al. Evaluation of the contribution of demographics, access to health care, treatment, and tumor characteristics to racial differences in survival of advanced prostate cancer. Prostate Cancer Prostatic Dis. 2019;22:125-36.

28. Epstein JI, Zelefsky MJ, Sjoberg DD, Nelson JB, Egevad L, Magi-Galluzzi C, Vickers AJ, Parwani AV, Reuter VE, Fine SW, et al. A contemporary prostate cancer grading system: a validated alternative to the Gleason Score. Eur Urol. 2016;69:428-35.

29. Jin S, Wang J, Shen Y, Gan H, Xu P, Wei Y, Wei J, Wu J, Wang B, Wang J, et al. Comparison of different lymph node staging schemes in prostate cancer patients with lymph node metastasis. Int Urol Nephrol. 2019;52:87-95.

\section{Publisher's Note}

Springer Nature remains neutral with regard to jurisdictional claims in published maps and institutional affiliations.
Ready to submit your research? Choose BMC and benefit from:

- fast, convenient online submission

- thorough peer review by experienced researchers in your field

- rapid publication on acceptance

- support for research data, including large and complex data types

- gold Open Access which fosters wider collaboration and increased citations

- maximum visibility for your research: over $100 \mathrm{M}$ website views per year

At BMC, research is always in progress.

Learn more biomedcentral.com/submissions 